Note: This article has been accepted in Children's Geographies. The version below may differ slightly from the published version, which should be regarded as definitive.

\title{
Navigating Children's Screen-time at Home: Narratives of Childing and Parenting within the Familial Generational Structure
}

\author{
Utsa Mukherjee, University of Southampton
}

This article draws upon my qualitative study with 8-to-12-year-old British Indian children and their professional middle-class parents, to demonstrate the ways in which parental mediation of children's digital leisure play out within the home. Using the relational lens of 'generational order', I identify the ways in which children 'navigate' their way around restrictive parental mediation of digital technologies just as parents 'navigate' multiple moral discourses emerging from media and policy circles imploring them to curb children's screen-time. Understanding these 'navigation' strategies around children's digital media use at home throws fresh light on parent-child relations, children's agency and their imbrications with wider generational structures. I conclude by arguing that greater empirical analyses of the relational aspects of parenting and childing are needed for Childhood Studies to fully appreciate the way generational structures inflect the lived geographies of childhood and parenthood in the context of children's home-based digital leisure.

Keywords: generational order, parenting, childing, children's agency, digital media, parental mediation, parent-child relations

\section{Introduction}

With the expansion in information and communications technologies (ICTs), children's engagement with digital media has attracted immense attention in popular discourses. Claims that digital media is turning children into 'digital zombies' and 'psychotic junkies' are 
ubiquitous in the news media, alongside appeals to parents to reduce their children's screen time which has been described as 'digital heroin' (Ives 2018; Kardaras 2016). These sensationalised media accounts have linked children's ICT use to the decline in their outdoor play as well to their physical and mental wellbeing (Azzollini 2017; Louv 2005).This amplified fear about the detrimental effect of ICT on children has been described by Finkelhor (2011) as 'juvenoia' which is largely driven by perceptions about all the possible dangers digital media make available to children rather than how real children actually use these technologies. This expansion in children's ICT use and the popular narratives surrounding it have transformed everyday family relationships and reconfigured the use of domestic spaces. Indeed, children's engagement with offline spaces and relationships are now increasingly mediated by their experiences of digital environments(Livingstone, 2009). These changes have also greatly impacted parents' lives and their parenting priorities (Lim 2020; Livingstone and Blum-Ross 2020). As parental responsibility vis-à-vis children's ICT use has come under greater scrutiny, parents in the West have taken on the added task of mediating their children's digital media use, thus attempting to manage the risks associated with it (Livingstone and Blum-Ross 2020Livingstone and Franklin 2018; Nikken and Schols 2015; Sonck, Nikken and De Haan 2013). While parental anxieties surrounding children's digital leisure - i.e. leisure timespaces based around ICT devices - and parental strategies such as limiting children's 'screen-time' are well documented, a detailed understanding of how children work around these restrictions and mobilise their digital leisure is thin on the ground. Furthermore, the extant literature on parenting and children's ICT use falls short of conceptualising parental mediation of children's digital leisure as a relational phenomenon. Therefore, in this article I draw on existing debates on parental mediation of children's screen-time and then put to work the relational framework of the familial generational structure to empirically unpack how children 'navigate' parental mediation strategies when it comes to their digital leisure at home and how parents in turn 
'navigate' their way in a climate where news media and policy interventions are constantly imploring them to take responsibility of their children's digital media use and curb 'screen time'. Such an empirical analysis of both parents' and children's narratives will form the basis for greater reflection on the dynamics of parent-child relation in the context of children's digital leisure and what it reveals about the workings of generational structures within families.

\section{Children, Digital Media, and Parental Mediation within the Home}

ICT devices have undergone radical transformation in recent years and have become pervasive within the home with a 'constellation of always-on and always-on-hand mobile media' encompassing the digitally connected family (Lim 2020, 2). These changes have wider implications for thinking about domestic space, family relationships and their imbrications with digital media. Consequently, the proliferation of these ICT devises within the home has spawned intense debates about the opportunities and risks they engender. Children have been at the heart of these debates both in terms of their status as 'digital natives' (Prensky 2001) and consumers of ICT, and because of their supposed vulnerability to the dangers of digital media and their inability to manage the risks that these devices pose (see Clark 2012; Livingstone and Blum-Ross 2020). In addressing these questions, scholars have more often than not turned to parents and investigated how they attempt to mitigate these risks and ensure the safety and wellbeing of their children. Children's experiences of dealing with parental mediation of their digital media use at home are only beginning to be understood. The emergent scholarship on children and ICT has developed in a number of different directions but given the remit of this article I will draw attention to two key aspects. First, I will focus on the polarities of risk and opportunities through which children's everyday use of ICT is constructed by adults. Then I will draw upon studies that look into how parents attempt to reduce risks and maximize the opportunities that come with ICT devices by mediating their children's ICT use. 
In a pioneering study of children's ICT use, Holloway and Valentine (2003) challenged the technological determinism that assumes that access to technologies will invariably produce fixed outcomes for children. Instead their empirical study revealed that children as competent social actors were using ICT to forge and enhance social relationships. Children were also identifying potential risks of online activities and coming up with ways to avoid them. Children, they argued, were more concerned with the influence of ICT on their lived identities at home and school and how these were perceived by their peers than they were about future job prospects that technological literacy can bring. These arguments have continued to frame the discussion around digital media within Childhood Studies. It has been repeatedly pointed out that notwithstanding how children employ ICT in their local context, children are largely constructed within the dominant adult-centric discourses as lacking an adequate sense of responsibility or emotional competence to match their growing technological abilities (Wyness 2012). Consequently, children are treated as particularly vulnerable to the new set of dangers including those around bullying, sexualisation and mental health that the internet and digital media have reportedly amplified (see Finkelhor 2011). The source of these new risks include 'adult stranger' as well as other children, thereby positioning children as simultaneously at risk and a potential threat to other children (Finkelhor 2011). These risk perceptions around digital media exist alongside the opportunities that ICT offers children at a time when technical skills are needed in multiple aspects of social life (see Livingstone 2009).

As younger children are becoming increasingly adept at using digital technologies for both schoolwork and leisure, parents have come to play a key role as mediators and gatekeepers of children's digital media experiences (Clark 2012; Livingstone and Blum-Ross 2020). The pervasiveness of mobile and digital media has enabled - what Lim (2020) describes as - the practice of 'transcendent parenting' wherein parenting obligations have broadened and urban middle-class parents are exploiting media technologies to assist their children, guide them 
through online spaces and keep an eye on them on an endless loop with little respite. Indeed, arguments suggesting that parents 'carry the primary responsibility for guiding their children's media behaviour' (Sonck, Nikken and De Haan 2013, 96) are ubiquitous, which serves to shift the responsibility from social institutions to individual parents to ensure that children are taking utmost advantage of the educational opportunities of digital media and are prepared for future careers in the media-rich society while avoiding its potential risks and harms (Livingstone et al. 2017; Livingstone and Helsper 2008). Driven by this need to maximize opportunities and minimize risks, parents are increasingly deploying a range of mechanisms to mediate their children's use of digital technologies. There is now a vast body of literature on how parents mediate children's use of the internet (Symons et al. 2017; Sonck, Nikken, and De Haan 2013; Livingstone and Helsper 2008), video-and-computer games (Martins, Matthews, and Ratan 2017; Friedrichs et al. 2015; Shin and Huh 2011), and television (Domoff et al. 2017; Schaan and Melzer 2015). These studies show that parents use three broad mediation strategies: active mediation, restrictive mediation, and co-using (see Livingstone et al. 2017). Active mediation involves parents openly talking to their children about digital media and its contents either to educate them about effective usage or to dissuade them from using certain devices or services (Sonck, Nikken, and De Haan 2013). Restrictive mediation entails setting rules in terms of location, medium or time-limit which restrict children's media use (Sonck, Nikken, and De Haan 2013). Co-use differs from the other two in the sense that parents here use media devices in the company of their children without using it as an opportunity to comment on its effects (Sonck, Nikken, and De Haan 2013). This debate around parental mediation has largely dealt with the relative effectiveness or popularity of these parental strategies within households across the class divide wherein middle-class parents have been found to be more anxious to curb the risks, distractions and time-waste wrought by digital media (Lim 2020; Clark 2012). This article shifts focus from questions about the need for or the efficacy of these parental 
mediation techniques, to ask a different question: How do both parents and their children navigate these parental mediation strategies within the home and how does it reshape parentchild relations. Empirically addressing these questions through the lens of 'generational order' - something the current literature lacks - will not only enrich our understanding of parental mediation of children's ICT use but also throw fresh light on the relational nature of parenthood and childhood in the context of the media-rich home. The focus on the home is crucial for research in the geographies of childhood has shown that children experience greater opportunities for participation at home than in school and community settings, and their relationship with parents is central to these participatory experiences (see Horgan, Martin and Forde 2020). By drawing attention to the home as the site for interrogating the relational dynamics of parental mediation and children's agency, this article takes the debate around parent-child relations and digital media to new directions. Thus, I will deal with the lived geographies of children's digital leisure/parental mediation, by foreground the spatial dimension of these processes.

\section{Understanding the Generational Order}

A useful way of conceptualising the parental mediation of children's digital leisure and children's responses to the same, is to view these processes through the prism of 'generational order'. The framework of the 'generational order' argues that childhood and adulthood are relational concepts and not mere 'age groups'. This creates affordances for understanding how children and adults - both at the individual level and as social groups - interrelate across age divisions (Mayall 2001). The notion of 'generation' is invoked here to unpack these interrelations between age-derived relational categories, for example the relation between parents and children at home or that between teachers and children at school (Alanen 2014; Mayall 2001). Generational structuring therefore names the social processes through which 
some people are constructed as children while others are constructed as adults; wherein 'constructions' entails agency of both children and adults and can be studied as a set of (material) practices (Alanen 2001). The notion of the generational order draws focus on how children and adults 'share the same world but from different locations, based largely on generation' (Leonard 2016, 132). Parent-child relations or teacher-child relations, in this sense, can be understood as types of adult-child relations which are in turn connected to other relational structures linked to class, gender, and race etc.

The generational order includes a range of more localised generational structures, for instance, the generational structure within the family which involves the child position and the parent positions (Alanen 2020). In this familial generational structure, the social relations are internal in the sense that both the parent position and the child position are dependent on one another; the existence of one presupposes the other (Alanen 2014). Although the power relation between the two positions is asymmetrical, holders of both generational positions continually inform, implicate, and shape each other's positional performance and identity (Alanen 2014; Leonard 2016). Thus, if the positional performance of those occupying the parent position within the familial generational structure - i.e. their intergenerational activities vis-à-vis children - is termed 'parenting', then “children's intergenerational activities and relationships in complement to those understood within the term 'parenting"' can be called 'childing' (Mayall, 1996: 49). Thus conceptualised, the framework of generational order takes us - both conceptually and methodologically- beyond the polarities of structure versus agency and help us grasp the interdependent and relational nature of children's lived geographies including their digital leisure lives at home. Relatedly, Punch $(2020,137)$ has recently mounted a robust critique of childhood researchers' lack of engagement with 'generational order' because of which 'the importance of generation and age as key social variables have become diluted' within Childhood Studies. She alsoadvocates greater dialogue between empirical work and 
theorising. Reflecting on Punch (2020), Holt and colleagues (2020, 127) call on childhood researchers to recognise the need for 'listening to other voices (parents, teachers, other adults) alongside the central ... role of highlighting young people's agencies'. Taking these challenges as my point of departure, in this article I empirically analyse both parents' and children's narratives around parental mediation of digital leisure to throw light on the workings of the familial generational structure and thereby identify the ways in which children's agency is articulated within inter-generational relationships. While there is now an emerging body of literature on parental mediation strategies, what sets this article apart is its operationalisation of the generational lens that juxtaposes narratives of parenting and those of childing vis-à-vis children's screen-time regulation.

\section{The Context of the Study: Aims and Methods}

In this article I report findings from a study with British Indian children and their professional middle-class parents living within the Greater London Urban Area. 12 children between the ages 8 and 12, alongside 18 parents across 10 British Indian families took part in the study. The larger project looked into the everyday leisure geographies of these children and attempted to unpack the subjective meanings parents and children attach to the latter's leisure activities. The fieldwork took place between the winter of 2017 and the summer of 2018. The materials presented in this article are drawn from the part of the study that dealt with children's use of digital media within the time-spaces of everyday leisure. We know from existing studies that children's digital leisure within the home is often mediated by parents. Therefore, the aim of this paper is to use the lens of 'generational order' to unravel the manner in which children's digital leisure experiences are mediated by middle-class British Indian parents and how children negotiate their way around these mediations. 
The study focused on the experiences of British Indian children since their accounts of digital leisure is under-explored in the exiting literature and we also know very little about parenting practices of minority ethnic middle-class parents (see Rollock et al. 2015). I recruited participants through British Indian Facebook groups, research champions in the community and through snowballing. In total, 10 families participated in the study. The families were all 'nuclear' two-parent households comprising of heterosexual married couples and children. The parents were all from the Indian ethnic background and were either born in the UK or migrated to the UK in the last two decades and were now British citizens. They all had university qualifications, were homeowners and were - with the exception of four housewives - middleclass professionals. Although no age-range is homogeneous, the age bracket of 8 to 12 years was used in recruiting child participants since it is neither too broad nor too narrow an age range to discern larger social patterns and draw out meaningful analytical points. The consent for children's participation in the study was obtained from both the child as well their parent and all names used in this article are aliases.

Given my interest in unpacking the narratives of parental mediation of children's digital leisure from both parent's and children's perspectives, I used semi-structured narrative interviews to capture those narratives. I conducted separate interviews with each parent, followed by a one-to-one interview with the child. The interviews with parents lasted between 45 minutes to an hour on average and those with children lasted between 30 to 45 minutes. The interviews with children were conducted one-to-onein most cases, with parents or other family members out of earshot. During the interviews, I asked both parents and children about their everyday routines and biographies and then proceeded to enquire about how the child spend their unstructured leisure time. In that context, I specifically asked children about the ICT devices they 'own' or use and how their parents approach this issue. . With parents, I enquired about the way they think about and mediate their children's digital media use. All interviews 
were audio-recorded with the written as well as verbal consent of the participants and were then transcribed verbatim.

The transcribed interviews were interpreted using narrative analysis (see Griffin and May 2018). I viewed the personal narratives under analysis 'to be socially produced in social contexts by embodied concrete people experiencing the thoughts and feelings of everyday life' (Plummer 1995, 16) and therefore I attended to the particularity of each narrative and the interplay of human agency therein. This approach to the data created affordances for unpacking the generational issues at play within the micro-geographies of parental mediation.Findings: Children's Digital Leisure at Home and the Familial Generational Structure

Interview narratives reveal that parents and children understand and interpret mediation strategies around children's screen-based leisure in different ways, which has wider implications for theorising parent-child relations in the media-rich home. The metaphor of 'navigation' here captures the way parents and children work around these mediation strategies. It lays bare the micropolitics of children's wayfinding in the face of parental mediation. At the same time, it also helps us appreciate the way parents too are navigating multiple layers of external interventions which continually implore them to curb their children's 'screen time'. In empirically unpacking both parents' and children's 'navigation' processes within the family home, I put to work a relational understanding of parenting and childing vis-à-vis parental mediation that builds on the works of Alanen $(2020,2014)$ and Mayall $(2001,1996)$ elaborated earlier.

\section{Childing, Navigation, and Digital Media Use}

When it comes to ICT devices, most parents in the study operationalised a restrictive mediation strategy which involved setting time limits on children's screen-based leisure. There was no 
reported instance in the data where parents actively monitored children's online activities afterwards or used digital technologies for surveillance. Although some younger children in the study were not allowed by their parents to own personal mobile phones, children regularly used a range of media technologies including computers, videogame consoles, and smarttelevision either by themselves or with other family members. As parents put in place restrictions on 'screen time', children came to navigate the time-restrictions in their own way, often carving out spaces which parents felt unable to physically monitor.

Aashka (8) lives in London with her parents - father, Alpesh (a software engineer) and mother, Swati (a dentist) - and younger brother Vineet (6). She does not have a personal mobile phone but has access to a tablet computer which she uses to watch videos and play games. Her usage of this tablet computer for leisure is, however, time-restricted by her parents who have adopted a policy of reducing her screen-time. Alpesh and Swati had both grown up in London and they regularly receive help with childcare from their own parents who now live in adjoining neighbourhoods. Alpesh works full-time and Swati part-time, and on the days they both go to work Alpesh's parents collect Aashka from school and look after her till Swati gets home. Aashka's grandparents are more lenient with screen-time than her parents and Aashka is aware of these differences. She exploits this opportunity to compensate for the restrictions that prevail in the presence of her parents. While talking to me about her daughter's ICT use and digital leisure activities, her father Alpesh reflected on this phenomenon:

She spends time with her grandparents and her brother [till we get home], and they just play. They watch things on tablets. We [my wife and I] don't allow them to watch tablets all the time. So they have restricted times on that when we are around, but we have no control over the times when the grandparents are there [and we are absent]. - Alpesh 
To fully unpack the generational issues at play here, it is an imperative to draw out the cultural dimensions of inter-generational relationships within Indian families. When it comes to Indian family lives, $\operatorname{Lamb}(2002,306)$ has shown that reciprocal love between generations is conceived of in terms of 'samman' (respect) which is 'a form of love flowing up from juniors to seniors' and 'sneha' (affection) which signals 'a form of love flowing down from seniors to juniors'. Therefore, depending on where you are positioned within the generational hierarchy, your intimate relationship with others in the family is defined either in terms of 'samman' or 'sneha'. The exchange of the two is not equivalent but equitable and 'samman' is entangled with the concept of generational hierarchy within the family. Similar ideas were echoed in Jutlla's (2013) study with Sikh families in Wolverhampton where people in their middle-ages - themselves parents - repeatedly emphasised the need to 'respect your elders' in relation to their own parents in a way that echoes Lamb's (2002) characterisation of 'samman' and upheld the 'position' of elders as an integral part of their cultural heritage even though most of them did not live in mutigenerational households. In my research, the parents' relations with their children were, as one mother in the study puts it, a 'mixed bag' of being 'cool', 'playful' and 'strict' with no expectation of or adherence to notions of hierarchical respect on the part of parents; the parents' relationships with their own parents however were embedded in the cultural perception of 'samman' for elders which in practical terms meant that parents like Alpesh - inter alia - did not enter into a conflict with their own parents over children's 'screentime'. At the same time, the expansive flow of 'sneha' from grandparents to grandchildren was instrumental in creating a more lenient disciplinary order where time-restrictions on tablet use is suspended. In these contexts, children navigate two layers of culturally coded generational structures, vis-à-vis their parents and grandparents, and use the opportunities afforded by latter to recompense for the restrictions that comes with the former. Children's agency therefore emerges as not only context-dependent but also complex and multi-layered, - fostered through 
immense reflexivity about the workings of culturally coded multiple generational structures and their concomitant power relations. In other words, children's agency is relational, and not independent or linear. This process of navigating time-restrictions on digital media use unfolds again in the case of 12-year-old Ankit who lives on the edge of London with his older brother Vishal (15) and parents, Shekhar (entrepreneur) and Jyoti (housewife). I visited his family home for interviews in the afternoon during the summer holidays. While I was interviewing his mother Jyoti one-to-one in the living room, Ankit knocked, came in and handed Jyoti his mobile phone. Jyoti then typed in the password and handed the phone back to Ankit. Ankit then left the room with a smile on his face. We continued with the interview and afterwards while telling me about Ankit's everyday life Jyoti referred to this incident and explained:

[A couple of months ago] He just started answering back. He wants things his way... That's why he was banned from using his phone. I've changed the password, that's why he came down to ask me the password... So yesterday I said to him 'You can have half an hour twice a day' so he gets it for one hour. And because he listened to me, I said today he can have it for 45 minutes twice a day because otherwise he was getting a bit bored.

In this case, time-limit on mobile usage is nested within a framework of reward and punishment. Owing to Ankit's perceived insolence, his mother Jyoti confiscated his iPhone which he got as a present last Christmas. Ankit uses his phone mainly to play games and to chat with his friends. Given that it was summer holidays, and he was spending most of the time indoors, these screen-based leisure activities gathered greater importance for him. This has possibly prompted Ankit to modify his behaviour towards his mother, in an effort to 'earn' his mobile 'privileges' back albeit with an attendant time-restriction. He has managed to impress his mother and move the time-limit from one hour to one-and-a-half hour per day. Jyoti too 
concedes that without his phone Ankit was getting a 'bit bored' during the summer holiday. But my entry into the domestic space reconstituted the temporal rhythm within the house since I had engaged his mother in a one-to-one interview in the living room for about an hour. He took advantage of the in-between time thus created, and got his phone unlocked by his mother. As Jyoti was busy with the interview and not keeping time of Ankit's mobile usage, he used that opportunity to work around the prevalent limits and 'squeeze' more time out of it.

Although Ankit's mother sets restrictions on the amount of time he can spend with his mobile phone, she does not monitor his online activities or filter the content available to him. He uses social media application like Instagram and Snapchat to stay connected with his friends, and there is no evidence in the data to suggest that Jyoti monitors these usages. Most of Ankit's mobile 'privilege' is spent playing games. At present, he regularly plays a mobile game named Fortnite and even watches a video blogger on YouTube called 'Ninja' who livestreams himself playing Fortnite every day. In discussing mobiles and games, Ankit tells me that 'I have an iPhone $\mathrm{x}$, so in my opinion it's the best gaming mobile thing that you can get. But there's not many mobile games, they should bring more mobile games out.' He is not only aware of the latest mobile technologies but also has current knowledge about which games are available on which platforms as he prefer playing Fortnite on his iPhone rather than on his XBox game console. Nevertheless, he puts his game playing and mobile usage in perspective and reports the following:

I have my own room. [But] I don't have any technology in my room apart from my phone. A phone has a lot of radiation. So, I don't play at night or something. - Ankit

Therefore, Ankit is not only navigating parental mediation but also actively managing potential risks from mobile usage at night that he has come to know about in a climate saturated with media reports on the supposed harms and risks posed by media 
technologies (see Blum-Ross and Livingstone 2016). This comports with findings of previous studies that children are aware of potential harms that can come from their use of digital technologies and in response they often devise forms of self-regulation (Green and Hannon 2007).

The instances above demonstrate that Aashka (8) and Ankit (12) in their own way and in response to their respective contexts work around screen-time restrictions imposed by their parents. Their narratives of wayfinding opens a window into the relational dynamics of parentchild relations wherein children do not simply follow or conform to parental restrictions but actively reflect on and find their way around those restrictions by either appealing to parents or by taking advantage of timespaces that their parents cannot physically police. The case of Aashka, for instance, further demonstrates how the parent-child generational structure within the nuclear family intersect with other generational regimes such as grandparent-parent relations and grandparent-grandchild relations which bear specific cultural connotations linked to these families' ethnic background. Children such as Aashka are aware of the power dynamics within and across these (multi-) generational structures, and they are capable of exploiting their affordances. Moreover, the children do not have an uncritical appraisal of digital media technologies. Instead, as Ankit's excerpt shows, children are aware of the risks associated with ICT use, and they do exercise forms of self-mediation. Equally, there is little evidence to suggest that children unequivocally prefer digital leisure above other forms of interactions or activities while parents are perpetually struggling to get their children to shun excessive digital media use. Such a simplistic narrative does not obtain, as 12-year-old Chirag's observation shows:

I especially like when we all play a board game together like Monopoly... It's a good chance to be with the family because most evenings ... she's [sister Anandi] on the laptop watching what she wants, I'm playing the Xbox for one hour plus, my dad is on 
his laptop or doing work on his phone and my mum is doing art ... [and] she's on her emails as well... It is very diverse, no one really talks to each other, everybody is doing their own stuff. So, I like when we do that together.

- Chirag

As much as Chirag (12) above argues in favour of more shared family leisure activities, his narrative equally manifests the complex nature of children's relationship with digital media as a form of leisure. With this nuanced understanding of childing and navigation vis-à-vis digital leisure, evidenced by the narratives of Aashka (8), Ankit (12) and Chirag (12), I will now illustrate the ways in which parents navigate multiple discourses and structures in parenting children's digital leisure time.

\section{Parenting, Navigation, and Children's Media Use}

Besides their generational position and identity vis-à-vis children (and grandparents) within the family, parents are also structurally positioned by the broader frames of cultural norms, the state and law. Thus, while talking to me about their children's digital leisure activities, parents in the study articulated a moral narrative of what their parenting obligations and priories were. For instance, in the extract below, Senior Dentist Swati talks about her eight-year-old daughter's habit of watching TV programmes and using her tablet to play video games or to watch YouTube videos:

I know that if you give her a computer or give her a tablet, she will quite happily just watch rubbish on YouTube and stuff. And it's just trying to get her away from that... And as soon as the TV is on, let's say if I'm busy doing something they can watch TV for hours and hours and just be brain dead. And it's like no, can you do something else instead. - Swati

Swati believes that extended exposure to digital media is harmful for her daughter, comparing its effect to being 'brain dead'. Her concerns echo the narrative of risk and harm that saturate the advice often given to parents with respect to digital media (Livingstone and 
Franklin 2018;Clark 2012). For instance, UK's National Institute for Health and Care Excellence (NICE) (2015) in its guidelines recommended that 'any strategy that reduces TV viewing and other leisure screen time may be helpful' (NICE 2015, 9) in keeping both children and adults healthy. It is in such a context that Swati feels concerned about the harms of TV viewing while not considering the opportunities that digital media might offer to children. This is an instance of 'juvenoia' that Finkelhor (2011) talks about. Indeed, as Jackson and Scott $(1999,86-87)$ rightly point out: 'the specific risks from which children must be protected serve to define the characteristics of childhood' at any given time. As we dwelt on this topic later in the interview, Swati revealed that she sees organised leisure lessons as a solution to this problem, as it channels her daughter Aashka's time into what Swati considers to be more productive pathways that carry opportunities for 'learning' skills and social competences. Thus, some leisure activities are deemed by parents as forms of 'shadow education' (see Park et al 2016) while other leisure practices such as screen-based digital leisure invoke risk-anxieties that warrant interventions. At the same time, family television time or watching films together as a collective family leisure experience is exempted by parents like Swati from this narrative of harm and is defined exclusively as a 'family practice' instrumental in cementing intimate ties and producing shared memories.

These risk-centric ideas about 'screen time' evident in Swati's narrative, is also at the heart of the latest guidance about 'screen time' issued to parents by the Royal College of Paediatrics and Child Health (RCPCH) (Viner, Davie, and Firth 2019, 6), which goes on to recommend that parents should 'ensure that exposure to screens by children and young people is subject to parental control.' These narratives and parental advice not only fuel intensive parenting practices (see Faircloth 2014), but also engender 'transcendent parenting' (Lim 2020, 4) whereby urban, middle-class parents are expected to transcend 'every online and offline environment their children transit through, be the voice of reason, and provide wise counsel 
along the way'. Swati therefore feels that letting her child indulge in unregulated digital leisure, infringes upon that narrative of ideal parenting. As a countermeasure, she directs her eightyear-old daughter into more 'productive' leisure activities at home and takes her to multiple organised leisure lessons that fills her after-school hours. This response is not exclusive to mothers, fathers in the study too exhibit similar moral framings of everyday parenting responsibilities apropos of digital media, as Suraj's (11) father Manoj’s says:

Your job [as a parent] is not just to take them to school, drop them off and then let them sit in front of the TV. Your job as a parent is to make sure they're engaged, able to fulfil anything that they choose to do.

As long as his children do not choose to 'sit in front of the TV' most of the time, Manoj - like other parents in the study - wants to provide them with every opportunity to participate in various structured leisure activities.. Being able to support his children in their leisure pursuits is a matter of pride for Manoj, as he goes on to say 'Whatever they want to do whilst we can afford it we're going to give them the option to decide whether they want to partake or not... In terms of time it doesn't make a difference ... Whatever they want to do ... I'll manage time.' Sitting in front of the TV, as Manoj puts it, or digital leisure more generally disrupts this narrative of being an ideal father, because digital media usage is not among the activities that are deemed beneficial for children. The same idea is reflected by 8-year-old Sonam's mother Divya:

I kind of keep them busy throughout the week, even after school. Because sitting at home is only TV time... which is good for a while. But I want them to learn different activities.

- Divya

The narratives of Swati, Manoj and Divya share the risk-centric appraisals of children's digital leisure and all three place a positive value on organised/non-digital leisure activities, 
describing the latter as 'productive'. These ideas underpin their attitude towards screen-based leisure and drive their strategy of imposing screen-time which in turn shape their relations with their children. Put differently, children's screen-based leisure at home sets off a moral crisis for parents, who are currently at the receiving end of relentless media coverage and policy interventions imploring them to take responsibility of their children's digital media use and help curb extended 'screen time' (Livingstone and Blum-Ross 2020; Livingstone and Franklin 2018; Blum-Ross and Livingstone 2016). It must also be noted that parents' mediation of children's screen-time sits within the wider apparatus of parental temporal regulation of children's lives - for example around going out, 'curfew times', and bed-times - that aims to keep children 'safe' and ensure that children make 'good use' of their time (Sarre 2010). These temporal mediation apparatuses rest on multiple factors such as location, time of day/year and age (Sarre 2010). In this study, the children were between the ages eight and twelve and I looked specifically at their digital leisure within the home. It is therefore possible that parents of children below or above this age range might adopt different mechanisms of mediating children's media use than that of screen-time restriction used by parents in this study.

The question of age further explains the lack of close monitoring of online activities of children. Children in most participating families use communal 'family' laptops or parents' mobile and computers to do homework, play games or simply to use the internet. Even when they possess a personal mobile, their 'screen time' is regulated rather than what they do during that 'screen time'.

Parents drew on the notion of 'trust' to justify their lack of close monitoring of what children do online while at the same time striving to minimise their children's duration of ICT use. Rather than being a contradiction, it uncovers the particularities of parent-child relations in the context of children's digital leisure. Aparna here explains her mediation of twelve-yearold daughter Koel's mobile usage: 
We have regular seminars at the school where they tell the parents that you must go through all your daughter's messages, I don't do that. But I trust her a bit and I expect her to tell us if something goes wrong. -Aparna

In a similar vein, nine-year-old Saumya's mother Nisha uses the notion of 'trust' to talk about Saumya's use of the internet. Although Saumya does not have a personal mobile phone, she regularly uses her mother's mobile and laptop:

My laptop is always here [in the living room]. So yeah ... sometimes teacher says like go and search this at home... So, she comes home and says mummy can I do that. I trust her. Because I know she won't do [anything wrong].

- Nisha

Parents, therefore, use this notion of 'trust' as an anchor while navigating the moral discourses of ideal parenting in relation to digital media and craft their own class-inflected practices of intensive parenting as described earlier. As public interest in the relation between 'good' parenting and children's digital leisure has grown, parents are increasingly formulating their own set of responses to these discourses and in so doing finding their bearing on the social world. Taken together, the parental narratives presented above offer insights into how parentchild relations are being (re)configured in the face of children's digital leisure: on the one hand it is about risk management through screen-time restrictions and on the other it is about the notion of 'trust' that encourages children to make appropriate use of digital devices within the screen-time allocated by parents. This demonstrates how children's digital leisure at home has redrawn the fault lines of parenting - infusing the latter with specific concerns around screentime, digital risks, and trust. 


\section{Conclusion}

In this article, I have explored how the pervasive presence of digital media technologies within the home has reshaped the positional performance of parents (i.e. parenting practices) and that of children (i.e. childing practices) and impacted parent-child relations. In exploring parental mediation strategies, scholars have repeatedly drawn attention to how this riskdriven approach of actively regulating and guiding children's digital media use is particularly prominent among urban middle-class families (see Lim 2020; Clark 2012). However, they have fallen short of unpacking how ethnicity and class intersect within the spaces of parental mediation. The findings reported here show that culturally coded and embodied notions of reciprocal love between generations within Indian middle-class families inflect parent-child, grandparent-grandchild and grandparent-parent relations which in turn reconfigures spaces of children's screen-time regulation within the home. In this way the article not only unravelled the workings of the familial generational structure, but also pointed to the way it intersects with the relational processes of class and ethnicity.

Using both parents' and children's accounts, I have shown that children do not simply reproduce parental narratives about media use. Instead, they 'navigate' the asymmetrical parent-child power relations in multiple ways- such as by exploiting the leniency exercised by grandparents - to create more opportunities for media use. At the same time, children also displayed awareness about possible health and social implications of continual ICT use and even provided examples of self-regulation. These findings have wider implications for thinking about the relational nature of children's agency - that children's social actions and wayfinding strategies are embedded within the affordances of specific generational ties. The empirical material therefore illustrates the way generation structures the social worlds that children inhabit and condition their relationship with adults - in this case parents. Children articulate their agency - through finding their way around parental restrictions on screen-time - within 
these multi-layered and culturally conditioned generational relationships, and therefore their agency cannot be accounted for without first understanding their relative positioning vis-à-vis adults (see Leonard 2016).

Taken together, these findings refine our current understanding of parent-child relations vis-à-vis children's digital media use. By putting the framework of 'generational order' to work, this article has facilitated a dialogue between empirical work and theory in this area. In doing so, it has taken forward the relational understanding of children's agency and opened new frontiers for future research into children's digital leisure and its concomitant parenting practices. 


\section{Bibliography}

Alanen, Leena. 2020. "Generational Order: Troubles with a 'travelling Concept'." Children's Geographies 18 (2): 141-143. doi:10.1080/14733285.2019.1630715.

Alanen, Leena. 2014. "Childhood and Intergenerationality: Toward an Intergenerational Perspective on Child Well-Being." In Handbook of Child Well-Being: Theories, Methods and Policies in Global Perspective edited by Asher Ben-Arieh, Ferran Casas, Ivar Frønes, and Jill E. Korbin, 131-160. Dordrecht: Springer.

Alanen, Leena. 2001. “Childhood as a generational condition: children's daily lives in a central Finland town." In Conceptualising Child-Adult Relations, edited by Leena Alanen and Berry Mayall, 129-143. London: Routledge.

Azzollini, Meena. 2017. "Declining physical activity levels in children and teens" Wellbeing, 10 July.

\section{https://www.wellbeing.com.au/body/fitness/declining-physical-activity-levels-children-}

teens.html

Blum-Ross, A. and S. Livingstone. 2016. Families and Screen Time: Current Advice and Emerging Research. Media Policy Brief 17 ed. London: Media Policy Project, London School of Economics and Political Science.

Buckingham, David. 2000. After the Death of ChildhoodOxford: Polity. 
Clark, Lynn Schofield. 2012. The Parent App: Understanding Families in the Digital Age. New York: Oxford University Press.

Domoff, Sarah E., Alison L. Miller, Neeaz Khalatbari, Megan H. Pesch, Kristen Harrison, Katherine Rosenblum, and Julie C. Lumeng. 2017. "Maternal Beliefs about Television and Parental Mediation in a Low-Income United States Sample." Journal of Children and Media 11 (3): 278-294. doi:10.1080/17482798.2017.1339102.

Faircloth, Charlotte. 2014. "Intensive Parenting and the Expansion of Parenting." In Parenting Culture Studies edited by Ellie Lee, Jennie Bristow, Charlotte Faircloth, and Jan Macvarish, 25-50. London: Palgrave Macmillan.

Finkelhor, David. 2011. The Internet, Youth Safety and the Problem of "Juvenoia". University of New Hampshire: Crimes against Children Research Center.

Friedrichs, Henrike, Friederike Von Gross, Katharina Herde, and Uwe Sander. 2015. "Parents' Views of Video Games: Habitus Forms in the Context of Parental Mediation." Journal of Media Literacy Education 7 (1): 58.

Green, Hannah and Celia Hannon. 2007. Their Space: Education for a Digital Generation. London: Demos.

Griffin, Ann and Vanessa May. 2018. "Narrative Analysis and Interpretative Phenomenological Analysis.” In Researching culture and society 4th ed., edited by Clive Seale, 511-532. London: Sage.

Horgan, Deirdre, Shirley Martin, and Catherine Forde. 2020. "Children's Voice in the Home: A Relational, Generational Space.” In Bringing Children Back into the Family: Relationality, Connectedness and Home edited by Sam Frankel and Sally McNamee, 41-56. Bingley: Emerald. doi: 10.1108/S1537-466120200000027004

Holloway, Sarah L. and Gill Valentine. 2003. Cyberkids: Children in the Information Age. London: Routledge. 
Holt, Louise, Matej Blazek, Matthew C. Benwell \& Lorraine Van Blerk. 2020. "Editorial introduction to Children's Geographies Sponsored lecture section: generational orderings and Geographies of Children and youth.”Children's Geographies, 18 (2): 125-127. doi: $\underline{10.1080 / 14733285.2019 .1694221}$

Ives, Laurel. 2018. "How to stop your children turning into digital zombies during the school holidays" The Telegraph, 17 July.

https://www.telegraph.co.uk/family/parenting/stop-children-turning-digital-zombies-schoolholidays/

Jackson, Stevi and Sue Scott. 1999. "Risk anxiety and the social construction of childhood." In Risk and sociocultural theory: new directions and perspectives, edited by Deborah Lupton, 86107. Cambridge: Cambridge University Press.

Jutlla, Karan. 2013. "Cultural Norms About the Roles of Older People in Sikh Families: A

Qualitative Study with the Sikh Community in Wolverhampton in the UK." In Indian Diaspora: Voices of Grandparents and Grandparenting edited by Amarjit Singh, 207-231. Rotterdam: Sense Publishers.

Kardaras, Nicholas. 2016. “'It's 'digital heroin': How screens turn kids into psychotic junkies” New York Post, 27 August.

https://nypost.com/2016/08/27/its-digital-heroin-how-screens-turn-kids-into-psychotic-junkies/ Lamb, Sarah. 2002. "Intimacy in a Transnational Era: The Remaking of Aging among Indian Americans." Diaspora: A Journal of Transnational Studies 11 (3): 299-330.

Lim, Sun Sun. 2020. Transcendent Parenting: Raising Children in the Digital Age. New York: Oxford University Press.

Livingstone, Sonia, and Alicia Blum-Ross. 2020. Parenting for a Digital Future. New York: Oxford University Press. 
Livingstone, Sonia. 2009. Children and the Internet: Great Expectations, Challenging Realities. Cambridge: Polity.

Livingstone, Sonia and Keely Franklin. 2018. "Families with Young Children and 'screen Time'." Journal of Health Visiting 6 (9): 434-439. doi:10.12968/johv.2018.6.9.434.

Livingstone, Sonia and Ellen J. Helsper. 2008. "Parental Mediation of Children's Internet Use." Journal of Broadcasting \& Electronic Media $52 \quad$ (4): 581-599. doi:10.1080/08838150802437396.

Livingstone, Sonia, Kjartan Ólafsson, Ellen J. Helsper, Francisco Lupiáñez-Villanueva, Giuseppe A. Veltri, and Frans Folkvord. 2017. "Maximizing Opportunities and Minimizing Risks for Children Online: The Role of Digital Skills in Emerging Strategies of Parental Mediation." Journal of Communication 67 (1): 82-105. doi:10.1111/jcom.12277.

Louv, Richard. 2005. Last Child in the Woods: Saving our Children from Nature-Deficit. Chapel Hill: Algonquin Books.

Martins, Nicole, Nicholas L. Matthews, and Rabindra A. Ratan. 2017. "Playing by the Rules: Parental Mediation of Video Game Play." Journal of Family Issues 38 (9): 1215-1238. doi:10.1177/0192513X15613822.

Mayall, Berry. 2001. “Introduction.” In Conceptualising Child-Adult Relations, edited by Leena Alanen and Berry Mayall, 1-10. London: Routledge.

Mayall, Berry. 1996. Children, Health and the Social Order. Buckingham: Open University Press.

National Institute for Health and Care Excellence. 2015. Preventing Excess Weight Gain. London: National Institute for Health and Care Excellence.

Nikken, Peter and Marjon Schols. 2015. "How and Why Parents Guide the Media use of Young Children." Journal of Child and Family Studies 24 (11): 3423-3435. doi:10.1007/s10826-0150144-4. 
Park, Hyunjoon, Claudia Buchmann, Jaesung Choi, and Joseph J. Merry. 2016. "Learning Beyond the School Walls: Trends and Implications." Annual Review of Sociology; Annu.Rev.Sociol. 42 (1): 231-252. doi:10.1146/annurev-soc-081715-074341.

Plummer, Ken. 1995. Telling Sexual Stories: Power, Change and Social Worlds. London: Routledge.

Prensky, Marc. 2001. "Digital Natives, Digital Immigrants Part 1." On the Horizon 9 (5): 1-6. doi:10.1108/10748120110424816.

Punch, Samantha. 2020. "Why have generational orderings been marginalised in the social sciences including childhood studies?" Children's Geographies 18 (2): 128-140. doi: $10.1080 / 14733285.2019 .1630716$

Rollock, Nicola, David Gillborn, Carol Vincent, and Stephen J. Ball. 2015. The Colour of Class: The Educational Strategies of the Black Middle Classes. London and New York: Routledge.

Sarre, Sophie. 2010. "Parental Regulation of Teenagers' Time: Processes and Meanings.” Childhood 17 (1): 61-75. doi: 10.1177/0907568209351551.

Schaan, Violetta K. and André Melzer. 2015. "Parental Mediation of Children's Television and Video Game use in Germany: Active and Embedded in Family Processes." Journal of Children and Media 9 (1): 58-76. doi:10.1080/17482798.2015.997108.

Shin, Wonsun and Jisu Huh. 2011. "Parental Mediation of Teenagers' Video Game Playing: Antecedents and Consequences." New Media \& Society 13 (6): 945-962. doi:10.1177/1461444810388025.

Silk, Michael, Brad Millington, Emma Rich, and Anthony Bush. 2016. "(Re-)Thinking Digital Leisure." Leisure Studies 35 (6): 712-723. doi:10.1080/02614367.2016.1240223.

Sonck, Nathalie, Peter Nikken, and Jos De Haan. 2013. "Determinants of Internet Mediation: A Comparison of the Reports by Dutch Parents and Children." Journal of Children and Media 7 (1): 96-113. doi:10.1080/17482798.2012.739806. 
Symons, Katrien, Koen Ponnet, Michel Walrave, and Wannes Heirman. 2017. "A Qualitative Study into Parental Mediation of Adolescents' Internet Use." Computers in Human Behavior 73: 423-432. doi://doi.org/10.1016/j.chb.2017.04.004. http://www.sciencedirect.com/science/article/pii/S0747563217302340.

Viner, R., M. Davie, and A. Firth. 2019. The Health Impacts of Screen Time: A Guide for Clinicians and Parents. London: Royal College of Paediatrics and Child Health. Wyness, Michael. 2012. Childhood and Society. 2nd edn. Basingstoke: Palgrave Macmillan. 